Fixed Point Theory, 20(2019), No. 1, 157-176

DOI: $10.24193 /$ fpt-ro.2019.1.09

http://www.math.ubbcluj.ro/ nodeacj/sfptcj.html

\title{
REMARKS ON FRINK'S METRIZATION TECHNIQUE AND APPLICATIONS
}

\author{
NGUYEN VAN DUNG*,**, TRAN VAN AN ${ }^{\dagger}$ AND VO THI LE HANG ${ }^{\ddagger}, \ddagger \ddagger$ \\ *Nonlinear Analysis Research Group, Ton Duc Thang University, Ho Chi Minh City, Vietnam \\ **Faculty of Mathematics and Statistics, Ton Duc Thang University, Ho Chi Minh City, Vietnam \\ E-mail: nguyenvandung2@tdtu.edu.vn \\ ${ }^{\dagger}$ Department of Mathematics, Vinh University, Vinh City, Nghe An, Vietnam \\ E-mail: tvandhv@gmail.com \\ ‡Faculty of Mathematics and Information Technology Teacher Education, Dong Thap University, \\ Cao Lanh City, Dong Thap Province, Vietnam \\ $\ddagger \ddagger$ Journal of Science, Dong Thap University, Cao Lanh City, Dong Thap Province, Vietnam \\ E-mail: vtlhang@dthu.edu.vn
}

\begin{abstract}
In this paper, we give a simple counterexample to show again the limits of Frink's construction [17, page 134] and then use Frink's metrization technique to answer two conjectures posed by Berinde and Choban [5], and to calculate corresponding metrics induced by some $b$-metrics known in the literature. We also use that technique to prove a metrization theorem for 2-generalized metric spaces, and to deduce the Banach contraction principle in $b$-metric spaces and 2-generalized metric spaces from that in metric spaces.
\end{abstract}

Key Words and Phrases: Metrization, quasi-metric, $b$-metric, 2-generalized metric, fixed point. 2010 Mathematics Subject Classification: 54E35, 54H25, 47H10.

Acknowledgment. The author are greatly indebted to anonymous reviewers for their helpful comments to revise the paper; to Prof. V. Berinde for his communication on [5, Conjecture 6.2] and for useful references; to Prof. S. Radenović for his comments on the metrization of 2-generalized metric spaces. The authors also acknowledge members of Dong Thap Group of Mathematical Analysis and Applications for their discussions.

\section{REFERENCES}

[1] H. Aimar, B. Iaffei, and L. Nitti, On the Macías-Segovia metrization of quasi-metric spaces, Rev. Un. Mat. Argentina, 41(1998), 67-75.

[2] T.V. An, N.V. Dung, Z. Kadelburg, Stojan Radenović, Various generalizations of metric spaces and fixed point theorems, Rev. R. Acad. Cienc. Exactas Fís. Nat. Ser. A Mat., 109(2015), 175-198.

[3] T.V. An, L.Q. Tuyen, N.V. Dung, Stone-type theorem on b-metric spaces and applications, Topology Appl., 185-186(2015), 50-64.

[4] A.V. Arhangel'skii, Mappings and spaces, Russian Math. Surveys, 21(1966), 115-162. 
[5] V. Berinde, M. Choban, Generalized distances and their associate metrics. Impact on fixed point theory, Creat. Math. Inform., 22(2013), no. 1, 23-32.

[6] M. Boriceanu, Fixed point theory for multivalued contractions on a set with two b-metrics, Creat. Math. Inform., 17(2008), no. 3, 326-332.

[7] M. Boriceanu, M. Bota, Adrian Petruşel, Multivalued fractals in b-metric spaces, Central Eur. J. Math., 8(2010), no. 2, 367-377.

[8] M. Bota, A. Molnár, and C. Varga, On Ekeland's variational principle in b-metric spaces, Fixed Point Theory, 2011(2011), 21-28.

[9] A. Branciari, A fixed point theorem of Banach-Caccioppoli type on a class of generalized metric spaces, Publ. Math. Debrecen, 57(2000), no. 1-2, 31-37.

[10] E. W. Chittenden, On the equivalence of ecart and voisinage, Trans. Amer. Math. Soc., 18(1917), no. 2, 161-166.

[11] E.W. Chittenden, On the metrization problem and related problems in the theory of abstract sets, Bull. Amer. Math. Soc., 33(1927), 13-34.

[12] S. Czerwik, Contraction mappings in b-metric spaces, Acta Math. Univ. Ostrav., 1(1993), no. 1, $5-11$.

[13] S. Czerwik, Nonlinear set-valued contraction mappings in b-metric spaces, Atti Sem. Math. Fis. Univ. Modena, 46(1998), 263-276.

[14] P. Das, L.K. Dey, Fixed point of contractive mappings in generalized metric spaces, Math. Slovaca, 59(2009), no. 4, 499-504.

[15] R. Fagin, R. Kumar, D. Sivakumar, Comparing top k lists, SIAM J. Discrete Math., 17(2003), no. 1, 134-160.

[16] S.P. Franklin, Spaces in which sequences suffice, Fund. Math., 57(1965), 107-115.

[17] A.H. Frink, Distance functions and the metrization problem, Bull. Amer. Math. Soc., 43(1937), no. $2,133-142$

[18] M. Jovanović, Z. Kadelburg, S. Radenović, Common fixed point results in metric-type spaces, Fixed Point Theory Appl., 2010(2010), 1-15.

[19] N. Kalton, Quasi-Banach spaces, Handbook of the geometry of Banach spaces 2 (W. B. Johnson and J. Lindenstrauss - eds.), Elsevier, 2003, 1099-1130.

[20] M.A. Khamsi, Remarks on cone metric spaces and fixed point theorems of contractive mappings, Fixed Point Theory Appl., 2010(2010), 1-7.

[21] M.A. Khamsi, Generalized metric spaces: A survey, J. Fixed Point Theory Appl., 17(2015), no. $3,455-475$.

[22] M.A. Khamsi, N. Hussain, KKM mappings in metric type spaces, Nonlinear Anal., 7(2010), no. 9, 3123-3129.

[23] L. Kikina, K. Kikina, On fixed point of a Ljubomir Ciric quasi-contraction mapping in generalized metric spaces, Publ. Math. Debrecen, 83(2013), no. 3, 1-6.

[24] W. Kirk, N. Shahzad, Fixed point theory in distance spaces, Springer, Cham, 2014.

[25] W.A. Kirk, N. Shahzad, Generalized metrics and Caristi's theorem, Fixed Point Theory Appl., 2013:129 (2013), 1-9.

[26] W.A. Kirk, N. Shahzad, Correction: Generalized metrics and Caristi's theorem, Fixed Point Theory Appl., 2014(2014), 1-3.

[27] P. Kumam, N.V. Dung, Remarks on generalized metric spaces in the Branciari's sense, Sarajevo J. Math., 10(2014), no. 2, 209-219.

[28] P. Kumam, N.V. Dung, V.T.L. Hang, Some equivalences between cone b-metric spaces and b-metric spaces, Abstr. Appl. Anal., 2013(2013), 1-8.

[29] P. Lo'lo', S. M. Vaezpour, J. Esmaily, Common best proximity points theorem for four mappings in metric-type spaces, Fixed Point Theory Appl., 2015:47(2015), 1-7.

[30] R.A. Macías, C. Segovia, Lipschitz functions on spaces of homogeneous type, Adv. Math., 33(1979), no. 3, 257-270.

[31] M. Paluszyński, K. Stempak, On quasi-metric and metric spaces, Proc. Amer. Math. Soc., 137 (2009), no. 12, 4307-4312.

[32] A. Petrusȩl, I.A. Rus, Fixed point theorems in ordered L-spaces, Proc. Amer. Math. Soc., 134(2006), no. 2, 411-418. 
[33] A.B. Pilarska, T.D. Benavides, The fixed point property for some generalized nonexpansive mappings and renormings, J. Math. Anal. Appl., 429(2015), no. 2, 800-813.

[34] S. Reich, A. J. Zaslavski, Genericity and porosity in fixed point theory: a survey of recent results, Fixed Point Theory Appl., 2015:195(2015), 1-21.

[35] V. Schroeder, Quasi-metric and metric spaces, Conform. Geom. Dyn., 10(2006), 355-360.

[36] T. Suzuki, Generalized metric spaces do not have the compatible topology, Abstr. Appl. Anal., 2014(2014), 1-5.

[37] T. Suzuki, B. Alamri, L.A. Khan, Some notes on fixed point theorems in $\nu$-generalized metric spaces, Bull. Kyushu Inst. Tech. Pure Appl. Math., 62(2015), 15-23.

[38] T. Suzuki, B. Alamri, M. Kikkawa, Only 3-generalized metric spaces have a compatible symmetric topology, Open Math., 13(2015), no. 1, 510-517.

[39] Q. Xia, The geodesic problem in quasimetric spaces, J. Geom. Anal., 19(2009), 452-479.

Received: May 11, 2016; Accepted: January 20, $201 \%$. 
